\title{
Walking on sunshine: Pairing electric vehicles with solar energy for sustainable informal public transport in Uganda
}

\author{
M.J. Booysen ${ }^{a, *}$, C.J. Abraham ${ }^{a}$, A.J. Rix ${ }^{a}$, I. Ndibatya ${ }^{a, b}$ \\ ${ }^{a}$ Department of E\&GE Engineering, Stellenbosch University, South Africa \\ ${ }^{b}$ Department of Computing \& Technology, Uganda Christian University, Uganda
}

\begin{abstract}
Minibus taxi public transport is a seemingly chaotic phenomenon in the developing cities of the Global South with unique mobility and operational characteristics. Eventually this wide-spread fleet of minibus taxis will have to transition to electric vehicles. This paper examines the impact of this inevitable evolution on a city-wide scale in Kampala, Uganda. We present a generic simulation environment to assess the grid impact and charging opportunities, given the unique paratransit mobility patterns. We used floating car data to assess the energy requirements of electric minibus taxis, which will have a knock-on effect on the region's already fragile electrical grid. We used spatio-temporal and solar photovoltaic analyses to assess the informal and formal stops that would be needed for the taxis to recharge from solar PV in the region's abundant sunshine. The results showed that the median energy demand across all simulated days of the fleet of taxis was $220 \mathrm{kWh} / \mathrm{d}$. This ranged to a maximum of $491 \mathrm{kWh} / \mathrm{d}$, with a median charging potential (stationary time) across taxis of $8 \mathrm{~h} / \mathrm{d}$ to $12 \mathrm{~h} / \mathrm{d}$. The median potential for charging from solar PV ranged from $0.24 \mathrm{kWh} / \mathrm{m}^{2}$ to $0.52 \mathrm{kWh} / \mathrm{m}^{2}$ per day, across the taxis. Our simulator and results will allow traffic planners and grid operators to assess and plan for looming electric vehicle roll-outs to the most-used mode of transport in Africa.

Keywords: Electric vehicle; Paratransit; Minibus taxi; Demand management; Renewable energy.
\end{abstract}

\section{Introduction}

"Urgent action is needed to identify sustainable pathways for the decarbonization of transport in SSA, in line with the United Nations (UN) Sustainable Development Goals (SDGs) and the Paris Agreement. ... Shifting to EVs [electric vehicles] could be eased by carefully co-locating additional local electricity generation with charging infrastructure, likely in the form of $P V$ [photovoltaics]. Investment into this infrastructure needs to happen concurrently with EV adoption. Yet, at present, ... this investment is hindered in part by the inability to accurately forecast the likely $E V$ demand for electricity, resulting in uncertain returns on investment." - Collett and Hirmer [1] in Nature Sustainability.

\footnotetext{
* Corresponding author

Email address: mjbooysen@sun.ac.za (M.J. Booysen )
} 
Paratransit plays a vital role as the primary form of transport in sub-Saharan Africa's public transit system. It transports more than $70 \%$ of the daily commuters and is a source of livelihood for many families [2]. Paratransit in the region takes various forms, such as minibus taxis, motorcycle taxis and bicycle taxis [3], with minibus taxis carrying the largest daily share of passengers [4. Powered by internal combustion engines, the taxis contribute greatly to the emission of greenhouse gases and a general decline of air quality in African cities [1, 5, 6].

The term "paratransit" means something wholly different in Africa's developing countries from the meaning used in developed countries; from its inception to its vehicle types to its operations. In developed countries, paratransit usually means a point-to-point flexible demand-responsive transport service customised with special requirements for the elderly and the disabled [4, 7]. For Africa's developing countries, paratransit "refers to demand-driven, unscheduled public transport provided by small operators, typically in mini- to medium-sized buses" [8]. Paratransit is a system which has evolved independently of the government, and is often considered informal. It operates somewhere between private passenger transport and conventional public transport in terms of cost, scheduling and route flexibility [9, 10, 11]. Besides minibuses, paratransit can also consist of single-passenger motorcycle taxis ("boda bodas") such as those in Kampala, or the tricycle taxis ("tuk-tuks") in Nairobi [12, 13, 14. Travel by paratransit accounts for approximately $70 \%, 90 \%, 91 \%$, and $98 \%$ of the road-based passenger trips in Johannesburg, Lagos, Kampala and Dar es Salaam, respectively [2, 15]. Of these paratransit trips, $83 \%$ are by minibus taxi $[15,16,17$. These minibus taxis are mostly old, second-hand imports from developed countries. For example, in Nigeria, the average age of light commercial vehicles (such as minibus taxis) is 24 years [18, p. 348]. The age and ubiquity of minibus taxis cause a serious environmental concern.

Furthermore, high levels of congestion can be found in cities of developing countries, due to high rates of urban migration. This congestion further exacerbates the carbon footprint of the transport sector, as vehicles sit idling in traffic for long periods of time. For example, as a result of high congestion, Uganda's transportation system emits $2 \mathrm{Mt}$ of $\mathrm{CO}_{2}$ per year, which is $38 \%$ of Uganda's total carbon emissions [19. The World Health Organisation classifies exposure to ambient air pollution (AAP) as a major threat to human health in sub-Saharan Africa, linking it to the increase in cardiovascular and cardiopulmonary diseases and lung cancer and respiratory infections [20, 21].

Developing countries typically have a very high urban population density, and urgent action is required to save lives and improve living conditions to an acceptable standard. The developing world consists of $86 \%$ of the global population and its vastness is shown in the map in Figure 1. This paper will contribute an approach to forecast the energy consumption of future electric public transport in developing countries. 


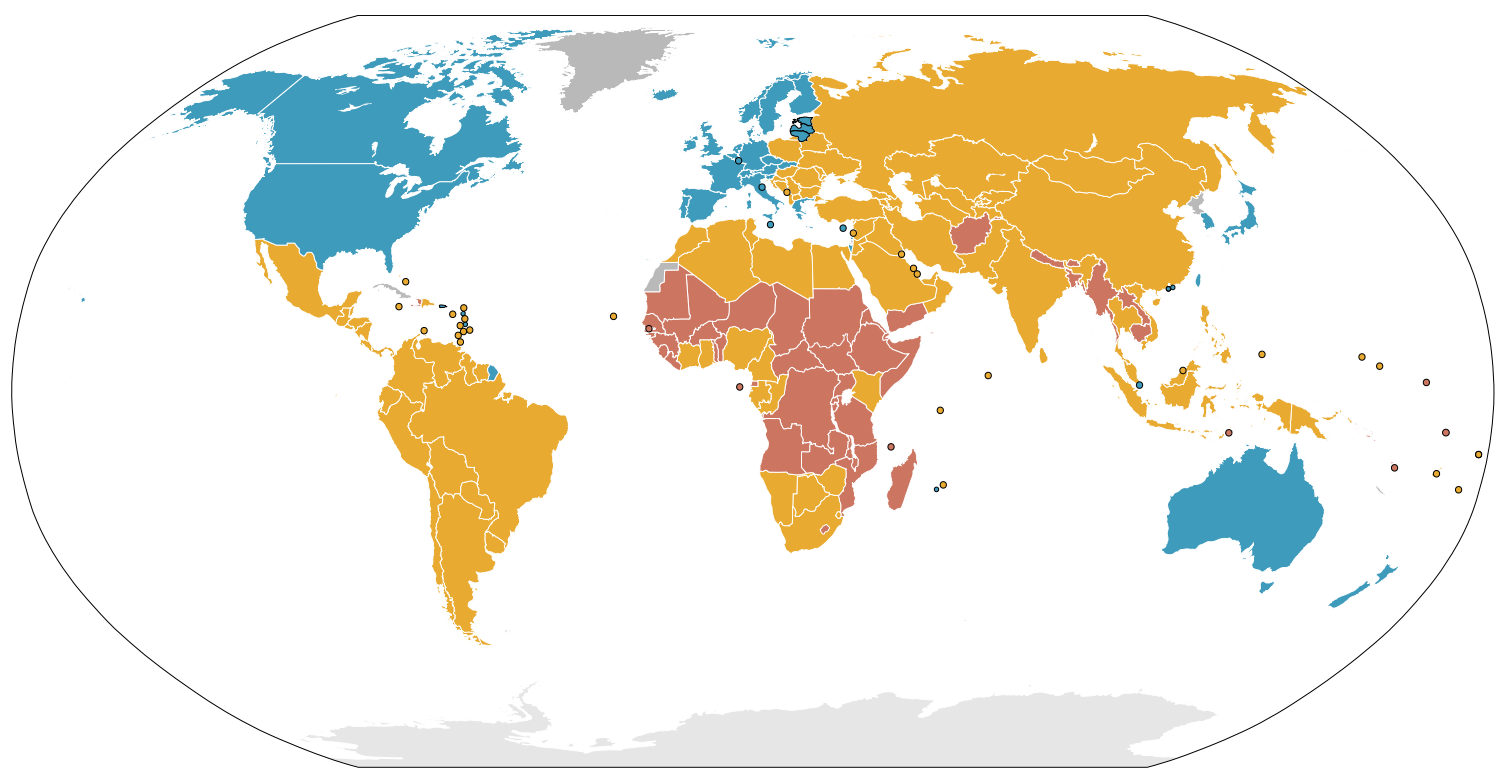

Figure 1: World map with countries classified by level of development. tries; $\square$ Developed countries. Source: Wikimedia Contributors 22

\subsection{Perspectives on sub-Saharan Africa's paratransit}

In sub-Saharan Africa, the public transport industry experienced two fundamental organic changes in the last quarter of the nineteenth century. The first was the shift of transport services proprietorship, from public to private, most often sole proprietorship, as a result of the World Bank's structural adjustment policies of the 1990s that restricted financing to state-owned entities, leading to their eventual collapse [23, 24, 25]. The second was the gradual introduction of low-capacity (five- to twenty-seater) passenger-carrying vehiclesminibus taxis-to fill the public transport vacuum 2, 8, 12, 14. Originating as a complementary transport service, the minibus taxis have become a way of life for the urban poor in several African cities.

Two competing views have broadly shaped discourse on the minibus taxis as part of the paratransit system in Africa. The predominant view is that minibus taxis and paratransit in general are the most extreme example of public transport failure in the developing world [26]. To support this view, terms such as "chaotic", "unsustainable", "unsafe" and "pollutants" are common in the literature in reference to the minibus taxis [27, 28, 29, 30. Consequently, proponents of this view advocate for a total overhaul of the minibus taxi industry and its replacement with western ideas of orderly transport, such as bus rapid transit (BRT) and light rail transit (LRT). Practically, however, this approach has faced massive resistance by existing paratransit operators, who have often used illegal means to cripple development of such systems. Besides that, the financial feasibility of BRT/LRT is disputed, as they require massive amounts of capital investment, which is often lost to corruption and mismanagement 8 . 
Proponents of the second view advocate for a hybrid future, with paratransit complementary to the scheduled BRT/LRT [31, 32. However, the adoption of this view is very slow and also facing resistance from paratransit operators. Although several benefits would accrue to them (such as job security for the drivers, proper regulation, and government subsidies), they would lose their autonomy and the elements of self-organisation that formed the core of the original paratransit in Africa.

An alternative third view is emerging, which imagines Africa's paratransit system as a complex adaptive system, composed of many interdependent components that interact non-linearly, often operating between "chaotic" and semi-orderly states [2, 33. This view acknowledges the coping mechanisms and innovative forms of self-organisation exhibited by paratransit and how the system adapts to serve the population's mobility needs with little or no centralised control. Actually paratransit "chaos" reveals to some degree the hidden order described by Hecht [34 as the "invisible governance ... that maintains competing agendas and aspirations in some kind of functional and parallel existence" [34].

The minibus taxi paratransit came into being to suit the mobile lifestyle of the urban poor in sub-Saharan Africa. It is unlikely that paratransit will be phased out of Africa's cities any time soon. They are ubiquitous and will continue for many reasons: their schedule flexibility, the urban sprawl, the irregular commuter movement patterns in urban spaces due to informal employment and the socio-cultural lifestyles of the urban poor in developing cities. However, the environmental cost of running these old internal combustion engine (ICE) vehicles is worrying. It has triggered discussions about the possibility of transitioning to electric minibus taxis as part of the global electrification and sustainability agenda [1, 5, 6, 35].

\subsection{The transition to electric vehicles and the electric minibus taxi}

The development of low-carbon transport in cities is crucial to the global agenda to combat climate change's various effects sustainably. Three of the seventeen United Nations Sustainable Development Goals - one, eleven and thirteen - are clean energy, sustainable cities and climate action [36]. The Intergovernmental Panel on Climate Change (IPCC) estimates that the transport sector generates $23 \%$ of the global energy-related greenhouse emissions. In sub-Saharan Africa the deteriorating air quality resulting from ambient air pollution and a high concentration of particulate matter $\left(\mathrm{PM}_{2.5}\right)$ is partly attributed to vehicle emissions [37, 38, 39]. The WHO estimated that 110,000 deaths in Africa in 2016 were due to air pollution - five times more than the total deaths caused by COVID-19 on the continent (as of Aug. 2021) [40, 41, 42]. Furthermore, Akumu [43. estimates the cost of air pollution in African cities to be as high as $2.7 \%$ of GDP.

Consequently, electrification is promoted as a low-carbon transport strategy to reduce combustion emissions and slow down the possibly damaging effects of climate change. In the same spirit, the transition to electric vehicles is gradually picking up in developing countries to the extent that some vehicle manufacturers are 
planning to phase out internal combustion engines. Sub-Saharan Africa is seeing a few isolated pilot electric vehicle projects, mainly focusing on micro-mobility (as motorcycles and tricycles), as well as buses and private cars [44, 45, 46]. At present, there is no known electric vehicle transition initiative targeting the paratransit industry, let alone the minibus taxis that are responsible for more than $80 \%$ of the public transport trips in the region.

This paper builds a foundation for evaluating the eventual impact of the transition to electric minibus taxis on cities' electrical grids, localised pollution, carbon footprint and taxi owners' profitability. Specific attention is given to the energy requirements of these vehicles, the potential distribution of charging stations and the potential electricity generation from renewable sources.

\subsection{Overview of earlier studies and approaches}

Initiatives to achieve sustainable urban mobility often follow a three-pronged transport decarbonisation approach, the "Avoid-Shift-Improve" paradigm [47, 48]. This approach aims to reduce trips, shift towards sustainable forms of transport (public transport, non-motorised modes and electric vehicles) and improve the transport-system's efficiency through infrastructure [49, 50]. In sub-Saharan Africa, the avoid and shift approaches have not been intensively studied [51]. The focus has been primarily on improvements: urban traffic management strategies such as widening roads, optimising road signalling and tightening lawenforcement $51,52,53,54$. Ironically, evidence from other world cities suggests that building freeways and roads around cities only increases car dependence and thus intensifies congestion and pollution [52]. Shifting to alternative, sustainable technologies, particularly by introducing electric vehicles in public transport and paratransit, is an approach that has been neglected. The literature on paratransit in sub-Saharan Africa focuses on aspects of sector governance [33] and regulation and reforms [8, 26, but seldom on operations [55], mobility characteristics [9] and the prospects of electric mobility integration [35, 47].

Research from outside the region shows that electric vehicles are three times more efficient than internal combustion engine vehicles and twice as efficient as hybrid vehicles [56, 57]. This efficiency is achieved partly by the efficient braking systems and elimination of idling losses and the consequent saving of energy for the vehicle's actual movement [57. Although debate continues on the economic and environmental trade-offs associated with electric vehicles [58], there is evidence of sustainable electric vehicle deployment. Some researchers argue that deploying electric vehicles shifts gasoline usage to coal-fired power generation, which exacerbates $\mathrm{CO}_{2}$ emissions by the power systems [58]. However, electric vehicle proponents counter-argue that, on a macro-scale, these vehicles' impact in terms of $\mathrm{CO}_{2}$ emissions depends mainly on the charging strategy and that the emissions can be reduced by optimising the use of renewable energy sources such as solar power [59, 60. In one of the scarce and isolated publications on electric vehicles in sub-Saharan Africa, 
Buresh et al. 60] note that South Africa (like many countries in the region) has high levels of insolation (the measure of solar energy at a place over a specified time), from between 4.5 and $6.5 \mathrm{kWh} / \mathrm{m}^{2}$ per day, with annual sunshine averaging more than 2500 hours. This implies that the region has an excellent chance of harnessing solar and other (existing) renewable energy sources to power electric vehicles. Indeed, projects researching alternative renewable energy have taken shape in the region [61, though not targeting electric vehicles for public transport services.

Two main research gaps remain in the literature on sub-Saharan Africa's transition to electric minibus taxis. One is the mobility characteristics of minibus taxis. As Quirós-Tortós et al. 62] observe, to estimate the charging requirements and vehicle performance of an electric vehicle we need to know its mobility patterns, such as distance, travelling time and idle time (or stopping time and duration). In other words, the vehicle's mobility has spatio-temporal dimensions. Apart from the findings of isolated studies on minibus taxi mobility, such as those by Ndibatya and Booysen [9, the general mobility dynamics of paratransit in sub-Saharan Africa are unknown. Although substantial gains have been made to capture mobility data of minibus taxis, such as those by DigitalTransport4Africa [63, they lack the necessary detail for individual electric vehicle analyses. The available datasets were presented in an aggregated format, and lacked the daily movement and stopping patterns of individual vehicles.

The second research gap is the lack of adequate studies on the region's potential for renewable energy from different sources such as solar PV, wind and bio-fuel as part of the ICE to electric minibus taxi transition [35, 61, 64, 65].

Due to the research gaps described earlier, the optimal sitting of the electric vehicle charging stations and PV installations has not been adequately studied in sub-Saharan Africa. Since the positioning of the PV stations depends on many factors, and since taxis routes may adapt to the charging station locations, this paper will not address this issue. However, we found that the approaches taken by current literature to determine common stopping locations of taxis could partially be used to solve the optimal EV charging stations sitting problem [11, 35, 66. From the sparseness of the work, it is clear that we lack information on the mobility of minibus taxis in sub-Saharan Africa and specifically the requirements of these minibus taxi fleets if they are converted to electric vehicles [1].

\subsection{Contribution}

To address the research gaps identified, we contribute our reproducible method for determining paratransit mobility and projecting estimates of electrical energy demand and the potential for renewable energy to meet that demand. This paper applied the technique to a specific case study in Kampala, Uganda. We assessed the electrical energy demand of the taxis using floating car data obtained from eight taxis over ten months. For 
three reasons, Kampala was chosen as a case study because it would benefit most from electric paratransit. Firstly, it has a large proportion of minibus-taxi travellers [2], and it has extremely poor air quality, attributed to high congestion and gridlock daily [67]. High congestion and high minibus-taxi ridership are hallmarks of urban cities in Africa. Other developing countries across the world may not use minibus-taxis. Still, the other forms of paratransit that they use can benefit from the approach taken in this paper to characterise their paratransit system's mobility. Once the movement patterns and stopping patterns are identified, subsequent steps of the methodology can be used to explore charging opportunities.

Secondly, like Kampala, most countries in sub-Saharan Africa are subject to high solar irradiance. Hence, Kampala's placement near the equator makes it a good representative of how solar energy can be used to help satisfy the energy demands of public transport electrification. For countries outside of Africa, in regions with less solar irradiance, the tools used in this methodology can be used to evaluate the potential of other renewable energy sources.

Lastly, since Uganda's energy grid is already $90 \%$ powered by renewable resources [68, it is in a good position to electrify vehicles. It is yet to be seen whether Uganda will be able to cope with the additional demand, without regressing to fossil fuels. Although Uganda has recently found some oil reserves, it also has ambitions to reduce its greenhouse gas emissions by $22 \%$ by 2030 [69. Hence, it is important to evaluate if existing renewable energy sources will be able to support the additional demand of mass vehicle electrification. This is even more important for other developing countries, such as South Africa and Nigeria, who rely on fossil-fuels extensively for electricity production, but still suffer frequent black-outs, due to being unable to meet pre-existing energy demand.

Our custom-built software, which we call eMBT-Sim, is used to perform analyses of vehicle mobility, solar PV models and electric vehicle models. We publish the software for free use and modification, subject to the terms of the GPLv3 license. Using the results obtained from this software, we estimate the impact on the Ugandan grid of converting all the minibus taxis in Kampala to electric vehicles, with and without solar augmentation.

\section{Method}

This section describes the dataset and the three models used for the research: the minibus taxi (MBT) mobility model, the photovoltaic (PV) model and the electric minibus taxi (eMBT) electric vehicle (EV) model. It describes the pre-experimental collection and analysis of the floating car data from a fleet of eight internal combustion engine minibus taxis. Inter-town MBT mobility modelling involved spatial clustering of floating car data to identify stopping events and generate routes between stops in preparation for PV and eMBT modelling. We present two model simulation setups for the EV and PV models and discuss 


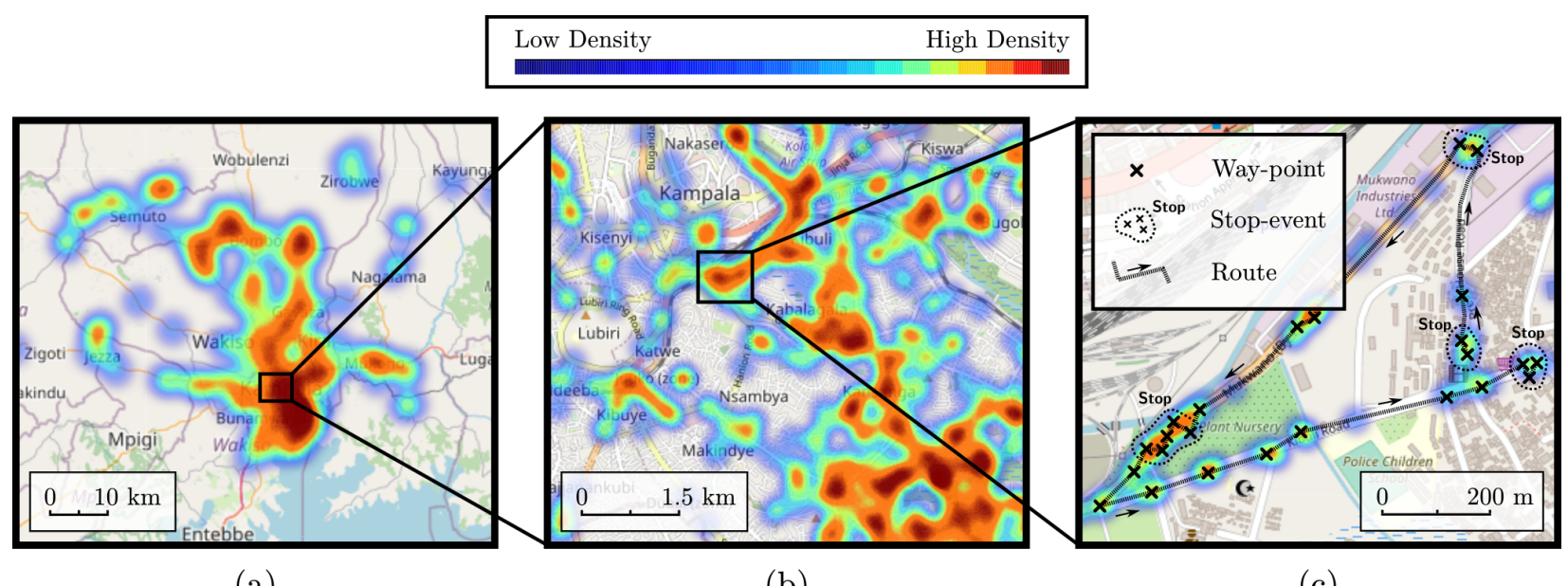

(a)

(b)

(c)

Figure 2: (a) Heat map showing the variation (by density) of floating car data; (b) Density of floating car data within the city of Kampala; (c) Illustration of way points, stop-events and route generation process.

their application to our urban paratransit context. The PV model was based on the System Advisor Model (SAM) developed by the National Renewable Energy Laboratory [70. We ran the PV and the EV models independently in a micro-transport simulator (SUMO) [71, 72, then recorded and analysed the eMBT energy and PV requirements for each simulated context.

A custom simulation software was written in Python to automate the steps in this methodology. The software is publicly available at: https://gitlab.com/eputs/embt-sim/

\subsection{Mobility}

The dataset consisted of floating car data obtained by tracking urban minibus taxis operating on routes in Kampala, Uganda. The area under study is defined by a box with coordinates $(0.170202,32.181182)$ and $(0.794505,32.852554)$. The area of study is shown in Figure 2 . The data was obtained using GPS tracking devices (viz.: Maestro MicroTracker MT-01), which were installed on a fleet of 8 MBTs for a period of 10 months. The data consisted of timestamped geographical-coordinates, altitude, speed and direction, logged at approximately one-minute intervals.

Due to errors in the data-capture, some MBTs in the fleet had fewer than 10 months of data. Furthermore, irrelevant data was removed from the dataset, viz. public holidays and weekends, as well as dates when the MBT left the area of study. After this, there was an average of 150 days of data per MBT.

\subsubsection{Identifying minibus taxi stops}

To generate the mobility patterns and establish the potential for charging at stops, it was necessary to identify stop-events from the GPS traces. Additional temporal analysis was required to determine the stop 
arrival-times and stop durations. We therefore categorised each datapoint as being either a way-point or part of a stop-event.

A stop-event in our work is closely related to the "stay point" defined by Zheng et al. 73 and Damiani et al. 74] and refers to a series of consecutive datapoints during which the MBT is considered stopped. Way-points are datapoints which define the route that the MBT must take when travelling between stops.

A stop-event begins when the taxi's velocity is below a threshold of $1 \mathrm{~km} / \mathrm{h}$, and ends when the taxi has either exceeded a velocity of $10 \mathrm{~km} / \mathrm{h}$ or drifted $25 \mathrm{~m}$ from the initial datapoint of the stop-event. The arrival-time of the stop-event is the timestamp of the initial datapoint in the series, and the duration of the stop-event is the difference between the timestamps of the first and last datapoints in the series. The result of this process is illustrated in Figure 2k. All the datapoints which do not belong to a stop-event are considered way-points, and will be used for generating routes for the EV model.

\subsubsection{Generating routes}

To simulate the mobility of MBTs and subsequently study their energy requirements, we generated routes linking the identified stops and the waypoints in the sequence recorded by the GPS tracker. A route is defined as a series of edges connecting the way-points and stops, while also specifying the times until which the eMBT should stop at each of the stops. The simulated eMBT follows these routes in order to simulate its mobility.

We used the stop-events and waypoints identified in Section 2.1.1 as well as the road-network, and SUMO's shortest path Dijkstra algorithm to generate the routes [71. The underlying road-network was imported from OpenStreetMap (OSM) 75], which included the road-segments (a.k.a. edges), intersections, speed limits, and traffic lights information.

For each taxi, each day's route was generated by traversing through the taxi's datapoints for that day. For each datapoint, the nearest edge on the road-network from the datapoint's coordinates would be found, and the shortest path from the edge of the previous datapoint to the current edge would be calculated. This path would be appended to the route being built. If the datapoint is part of a stop-event, the route would also specify that the eMBT should stop at the current edge until the timestamp of the current datapoint. This process is illustrated in Algorithm 1.

The paths between the sources and destinations of interest were computed using SUMO's implementation of the Dijkstra algorithm [71. This algorithm searches for the route with the least cost [76], where the cost can be the distance, time, or projected-electricity-consumption required to traverse from source to destination. In this study, we defined the cost as the distance, as it was the simplest cost to calculate. 


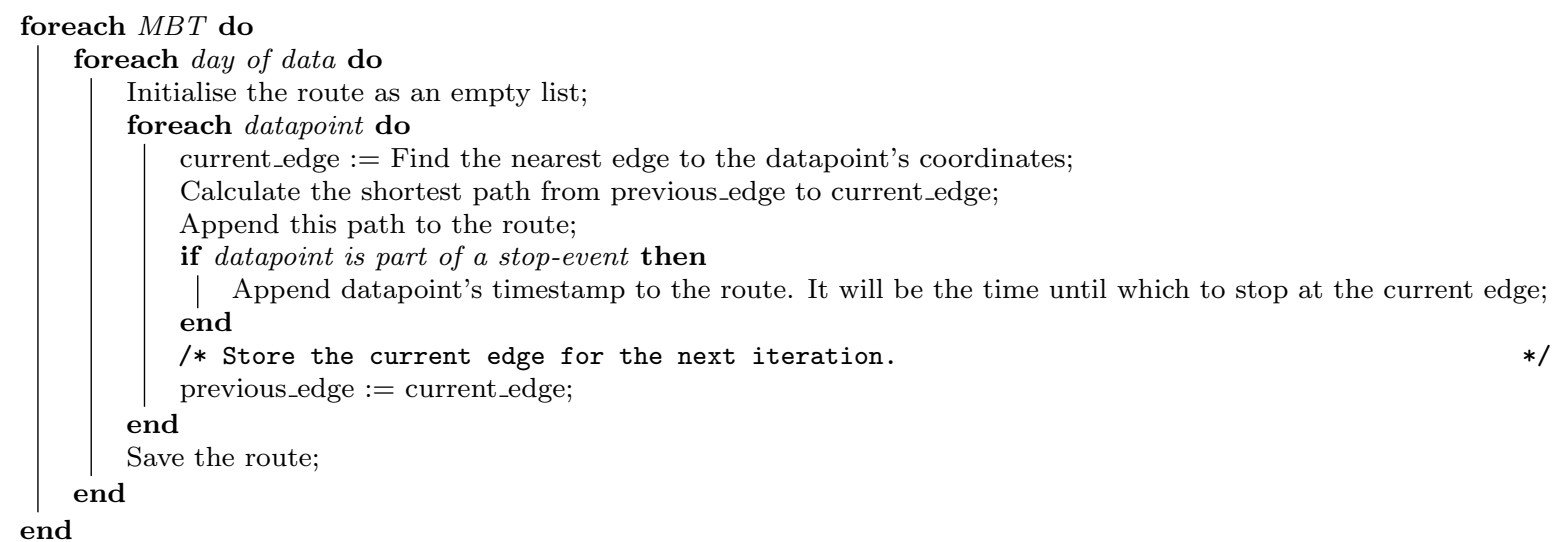

Algorithm 1: Routing algorithm.

\subsection{The eMBT EV model}

We set up a simulation model using a custom SUMO electric vehicle simulation model, to measure the temporal variation of power and energy usage and the relationships between power consumption and eMBT speed. The model's parameters were specified to match the prevailing MBT used in sub-Saharan Africa, the Toyota Quantum. The weight and front surface area were measured from a Toyota Quantum minibus taxi. We approximated the rest of the parameters according to the recommendations by Fridlund and Wilen [77. These parameters include: height $2.3 \mathrm{~m}$, width $1.9 \mathrm{~m}$, front-facing surface area $4 \mathrm{~m}^{2}$, weight $2900 \mathrm{~kg}$, constant power intake $100 \mathrm{~W}$, propulsion efficiency 0.8 , recuperation efficiency 0.5 , roll drag coefficient 0.01 and radial drag coefficient 0.5. The simulation program initialised the eMBT model for each date that was simulated. The eMBT model was applied to the generated routes. For every second of simulation time, the simulator outputted the energy consumption and speed of the eMBT as it progressed along its route.

With an average of 150 days of data per taxi, the volume of output data from the model was huge. Our goal was to obtain useful metrics that would summarise this data. The first metric we considered was the average power usage profile of the whole eMBT fleet. Such a profile would indicate how much power the eMBTs used at various points in time. This profile would be indispensable, for example, for testing the hypothesis that there would be a good charging opportunity during the day. It would also show what order of magnitude the battery size should be. We calculated the profile by obtaining the power-vs-time profile for each day, averaging this across all days for each eMBT, and then averaging that across all eMBTs in the fleet. The profile was plotted with respect to time.

\subsection{PV model simulation setup}

We set up the SAM-based PV model to calculate the energy available from photovoltaic sources and to study the daily charging potential for each eMBT in a synthetic fleet of eight eMBTs. The model generates 
the plane-of-array solar irradiance profile based on radiometric data, solar azimuth angle, and photovoltaic panel tilt angle. We used radiometric data for a year sampled every 15 minutes from the National Solar Radiation Database [78. The tilt angle was set to $3^{\circ}$, South facing, which is the optimum tilt angle suggested by Jacobson and Jadhav [79].

To get the output power profile of the PV array, a $16 \%$ system efficiency was applied to the irradiance profile, i.e., $20 \%$ and $80 \%$ were used for the solar panel and balance of the system (including the inverter), respectively. We used the stop-event analysis from Section 2.1.1 to further analyse the battery charging potential from solar PV by evaluating the times at which the stop-events occurred and their durations. We first applied thresholds to filter out stop-events with durations above 8 hours or below 20 minutes. This was to ensure that stop-events irrelevant to our study did not skew the results. These stop-events were grouped according to the spatial cluster in which they occurred, and temporal clustering was done within each spatial cluster to obtain spatio-temporal clusters.

Based on the stop-events detected during the spatio-temporal clustering, we computed the potential energy sourced from PV per day. For each eMBT stop-event, the PV output-power-profile was integrated from the beginning to the end of the stop-event in order to calculate the total energy that could be charged from PV during that stop-event. The PV energy of each stop-event was summed to get the total energy that could be charged from PV for that day as a function of the area of the PV array. These "daily PV charging potentials" were aggregated for each taxi and plotted as box plots. This metric allowed us to approximate the size of the PV array required to provide a certain percentage of an eMBT's energy demands.

\section{Results and discussion}

This section describes the results obtained from applying our three models to the floating car data of Kampala and its surrounds. The results obtained refer specifically to the MBT mobility, the eMBT's power requirements and the potential charging opportunities. The charging opportunities are separated into stop times for the purpose of source-ambivalent charging, and potential charging from PV.

The MBT mobility modelling provides the identified stop-events that serve as input to the PV modelling while generating routes used to determine the power requirements of the individual eMBT and the fleet of eMBTs.

\subsection{Mobility analysis}

The movement patterns of a minibus taxi is a key factor in deciding the taxi's suitability for electrification. The first step in this analysis was to identify the stopping patterns of the minibus taxis. The stops identified from this step are shown in Figure 3 . The plots show the arrival time and duration of all stops encountered by 
each of the taxis. Stops shorter than 20 minutes were filtered out from these plots, since they are unsuitable for charging, as well as stops longer than 8 hours, since they do not constitute normal taxi behaviour.

The scatter-plot displays seemingly chaotic patterns, so box-plots of the stop-duration are overlaid for each hour of the day. The box plots reveal that, for all the taxis except T13, $50 \%$ of their stops are less than one hour long. Some taxis also indicate that they stop longer at certain times of the day than others. For example, T14 has a larger stop-duration at around 8-11 am and likewise for T24 at around 12-14 am. This could indicate that these are the times that the taxis wait for their passengers to board. Also, some taxis, such as T13, have a very high variance in their stop-duration, which could indicate that they serviced a different route, or that the taxi needed to wait longer for it to fill up with passengers.

The stops identified in this step were also aggregated into a box-plot which shows the total daily stopduration for each of the taxis. This is shown in Figure $5 \mathrm{~b}$. Although the scatterplots indicated that most taxis stopped for short durations for each of their stop-events, the box-plots indicated that overall, the taxis spent a large proportion of their day stopped. The box-plots showed that the mean stop duration is 9.7 hours per day (40\% of the day). We see, for example, that taxis T06 and T08 stop for the longest time (around 12 hours per day), while Figures $3 \mathrm{~b}$ and $3 \mathrm{c}$ indicate that their stop-events are relatively short (less than 1 hour each). This reveals that the taxis stop frequently, for relatively short periods.

\subsection{Energy analysis}

The output of the EV simulation is shown in Figure 4. The mean instantaneous power demand versus time of a working weekday is shown in Figure 4 a. "Power demand" refers to the net power drawn from the vehicle's battery. A clear typical temporal profile is apparent for the minibus taxis, closely matching the expected peak traffic hours.

There is a morning peak demand period from $7 \mathrm{am}$ to $9 \mathrm{am}$, with a peak value of $15 \mathrm{~kW}$. A diminished demand with a mean of around $10 \mathrm{~kW}$ is observed from $11 \mathrm{am}$ to $4 \mathrm{pm}$, constituting a period of reduced activity and demonstrates the potential for solar charging. A gradual increase to another pronounced peak value of $17 \mathrm{~kW}$ between $7 \mathrm{pm}$ and $9 \mathrm{pm}$ follows, and this flatter evening demand profile slowly declines to return to less than $3 \mathrm{~kW}$ by midnight. Complete inactivity is observed from midnight to $5 \mathrm{am}$. This indicates that there is around 5 hours for charging during night-time hours. It is clear that the taxis are active for a very long period of the day. This corresponds to the qualitative study done by Spooner et al. [80, p. 29] which showed that some taxi drivers in Kampala worked for more than 15 hours per day.

This temporal profile indicates the energy demand requirements of the eMBTs, and already hints at some charging potential during the evening - probably from grid power - and some during the middle of the day - preferably from solar power. 


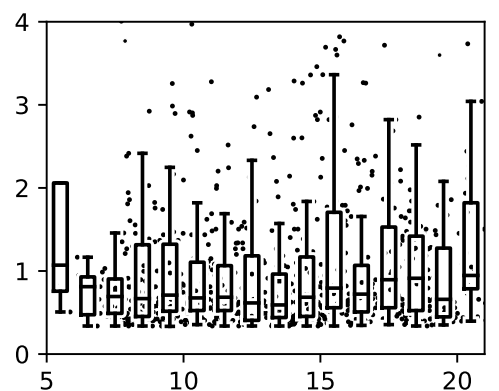

(a) T05

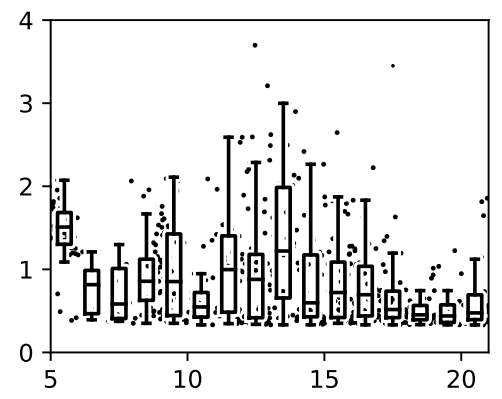

(d) T09

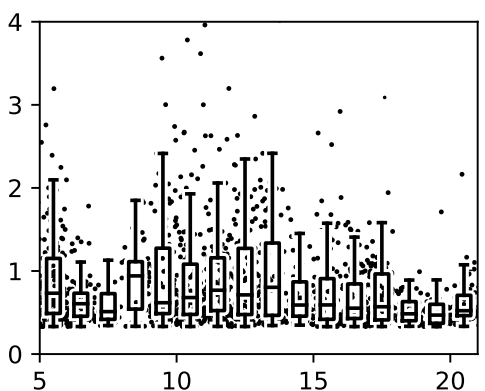

(b) T06

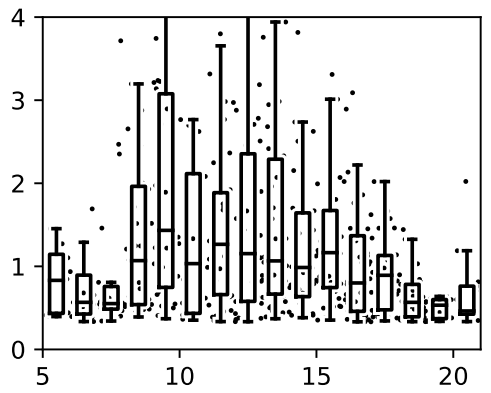

(e) T13

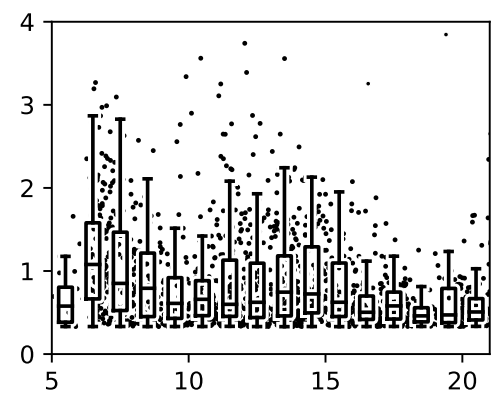

(c) T08

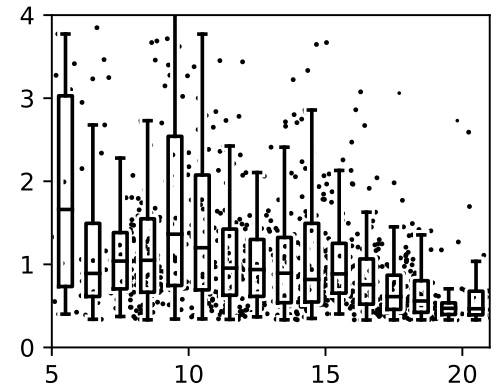

(f) $\mathrm{T} 14$

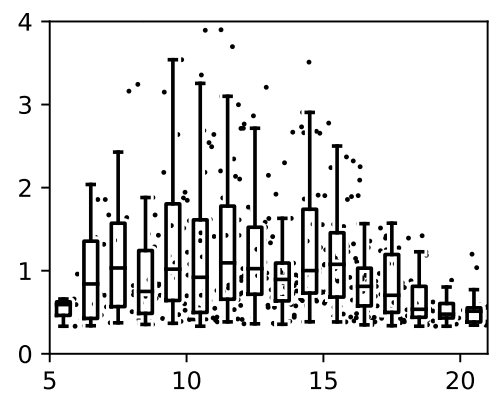

(g) T23

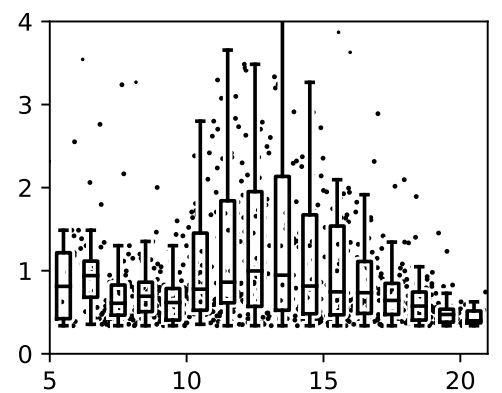

(h) T24

Figure 3: Scatter plot of stop-events. The duration of each stop (in hours) is plotted on the vertical axis and the arrival time (hour of day) of the stop is given on the horizontal axis. Box plots of stop-duration for each hour of the day are overlaid on the scatter plot.

The distribution of power profiles across the eight taxis is shown by the shaded area, labelled Power Distribution. The distribution shows that most of the taxis follow the trend of using more power during the morning and the evening.

Figure 40 shows the mean instantaneous speed of the MBTs versus time of the day. The similarity of this plot to the power profile highlights the substantial impact of speed on power draw. The energy required was close to linearly proportional to the distance travelled, which demonstrates that a simpler distance-based model would have provided good estimations and required substantially less processing power. The mean energy required per day was $220 \mathrm{kWh}$, and the mean distance was $224 \mathrm{~km}$ (obtained by integrating the power and speed profiles respectively). 


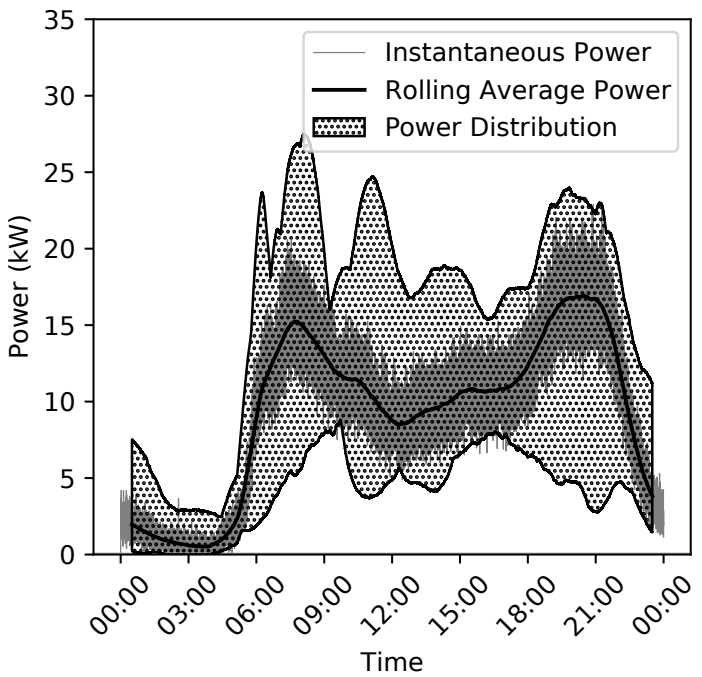

(a)

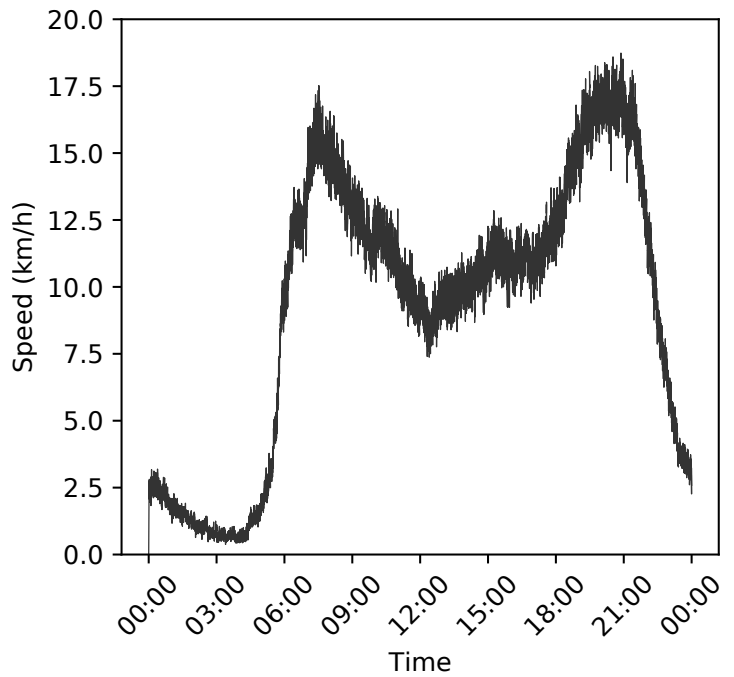

(b)

Figure 4: Summary of electrical requirements for all the simulated eMBTs (a) Daily power (instantaneous and rolling average) sampled per second; (b) Speed vs time

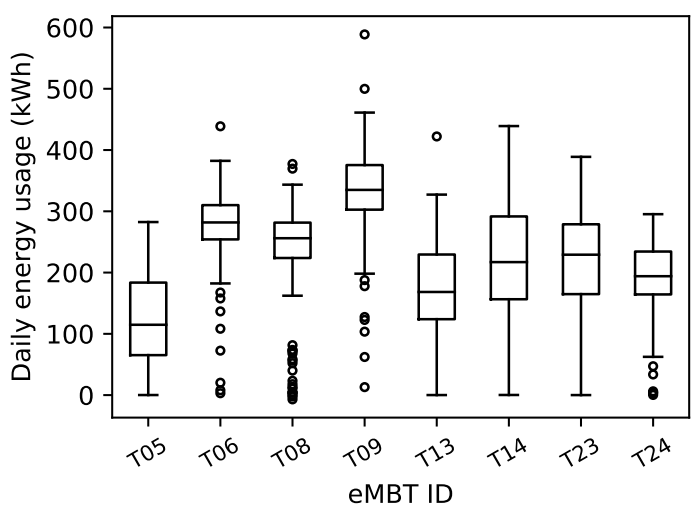

(a) Energy used per eMBT.

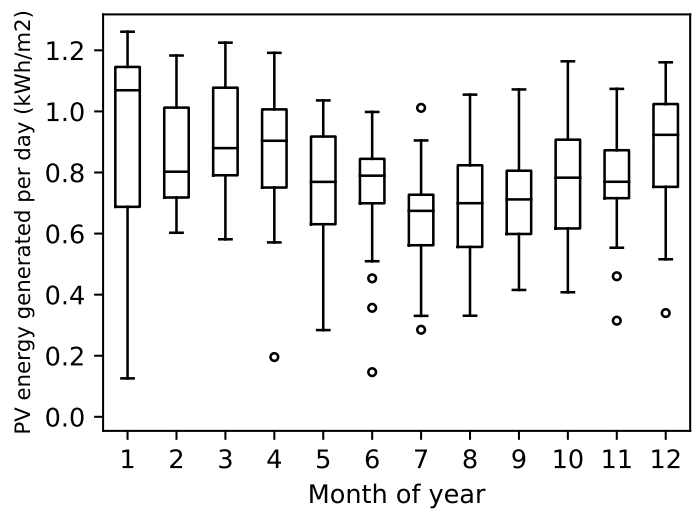

(c) PV generation per $m^{2}$ per month.

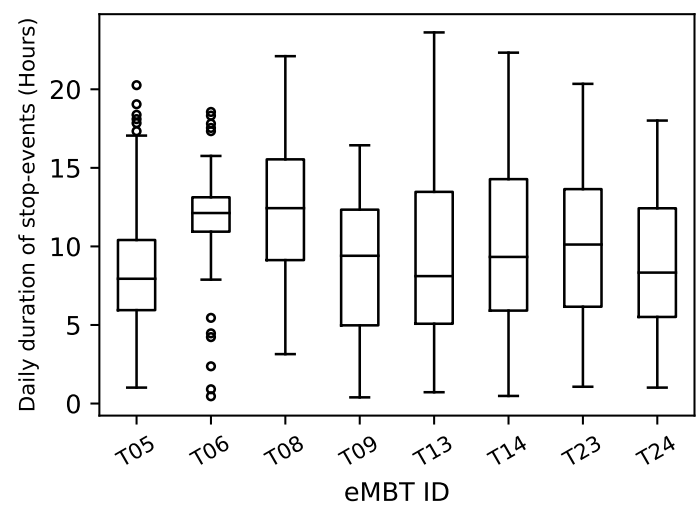

(b) Durations of stop-events per eMBT.

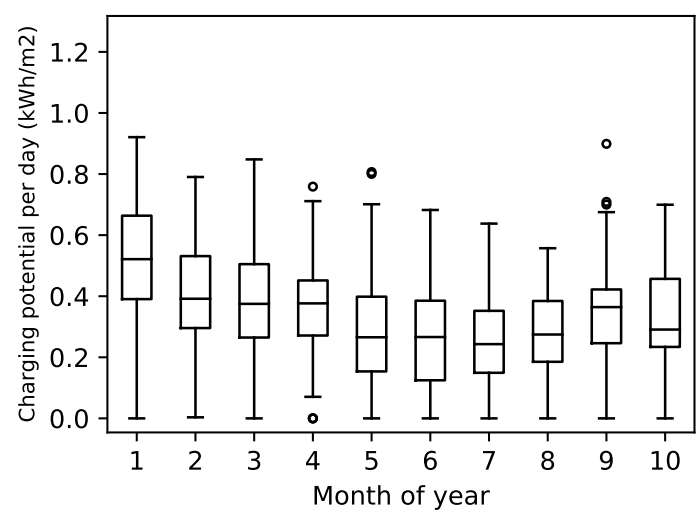

(d) PV charging potential per eMBT per $m^{2}$ per month.

Figure 5: Summary of mobility, energy requirements, and charging potentials of taxis in Kampala. 
The distribution of energy usage per day, is shown in Figure 5a for each of the eight taxis. The taxis' energy usage is similar, with the median energy per taxi per day across all taxis ranging from $108 \mathrm{kWh}$ to $335 \mathrm{kWh}$, with the mean of the medians equal to $220 \mathrm{kWh}$. The taxis travelled a mean distance of $224 \mathrm{~km}$, leading to an energy efficiency of $0.98 \mathrm{kWh} / \mathrm{km}$.

For seven of the eight taxis, there is a $75 \%$ probability that the taxi will use less than $314 \mathrm{kWh}$ on a given day. For the eighth taxi, the 75 th percentile energy-usage is $375 \mathrm{kWh}$. However, up to $491 \mathrm{kWh}$ would be needeed to meet the energy demand of all (non-outlier) days for all the taxis.

These results indicate that the demand is much bigger than the batteries of currently available passenger electric vehicles. In order to reduce the battery size and capital costs of the vehicle, it would be necessary for eMBTs to charge at various stops during the day. However, the results do seem plausible, as the mean energy efficiency of these minibus taxis $(0.98 \mathrm{kWh} / \mathrm{km})$ sits in-between the energy efficiencies of light electric vehicles and large electric buses 81

\subsection{Charging potential}

A sizable eMBT fleet could place a substantial burden on the local electrical network and power generation capacity of countries in sub-Saharan Africa. The strain on the local utility could cause infrastructure and electrical supply problems, so we investigated the opportunities for charging these vehicles from solar PV systems. To discover the eMBTs' opportunities and requirements if they are to charge during stationary periods, we did a 24-hour analysis of the start times and the durations of stop-events. The analysis shows what the average charger capacity should be if a vehicle is charged using only power from the local electrical utility. We applied a minimum stop duration of 20 minutes and a maximum stop duration of 8 hours per event to ensure that only valid operational stops would be identified and that drop or pick up and go events were not included as charging opportunities. We chose the maximum of 8 hours because a taxi in normal service would not stop for longer than that on a week day.

\subsubsection{Charging from the grid}

Figure $5 \mathrm{~b}$ shows the distribution of stop-events across days, with the minimum and maximum stop duration thresholds applied. The figure shows that the MBTs' cumulative stop duration times vary considerably, with the median duration per day ranging from a minimum of $8 \mathrm{~h}$ for taxi T05 to a maximum of $12 \mathrm{~h}$ for taxi T08.

To calculate the charger capacity we used a relatively high energy demand and a relatively short charging time for an averagely demanding situation. We used the averages of the $75^{\text {th }}$ percentile of the energy usage (Figure 5a) and the $25^{\text {th }}$ percentile of the 24-hour stop duration times (Figure 5b) as $273 \mathrm{kWh}$ and $6.7 \mathrm{~h}$ respectively to calculate a charger capacity of $40.6 \mathrm{~kW}$. This assumes a constant charging profile for the 
sake of simplicity, as a real EV charging profile would require additional modelling. With these assumptions, $40.6 \mathrm{~kW}$ for $6.7 \mathrm{~h}$ would fully recharge a taxi on most days.

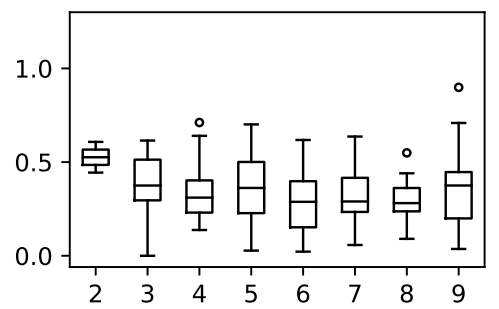

(a) $\mathrm{T} 05$

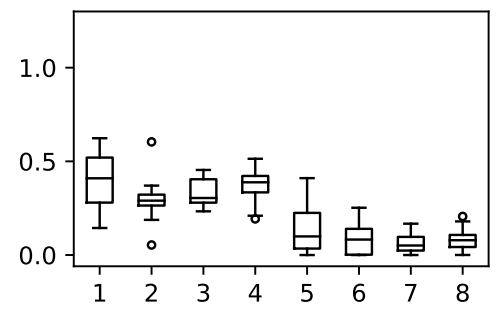

(d) T09

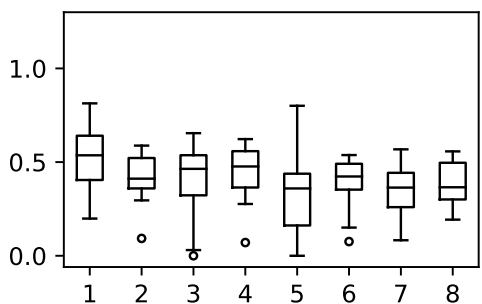

(b) T06

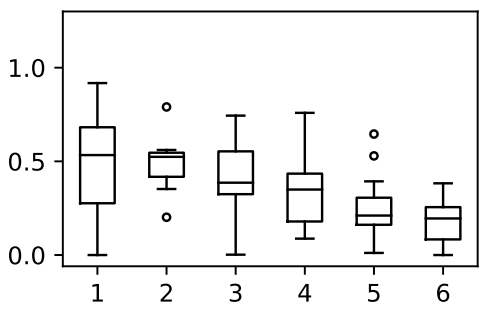

(e) T13

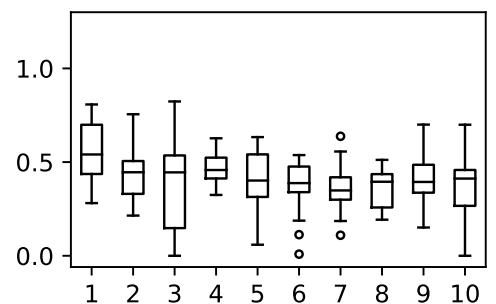

(c) T08

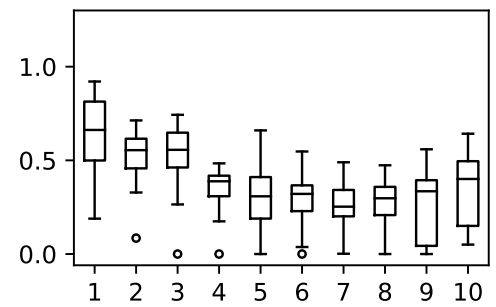

(f) $\mathrm{T} 14$

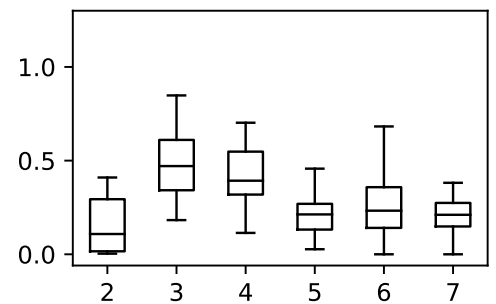

(g) $\mathrm{T} 23$

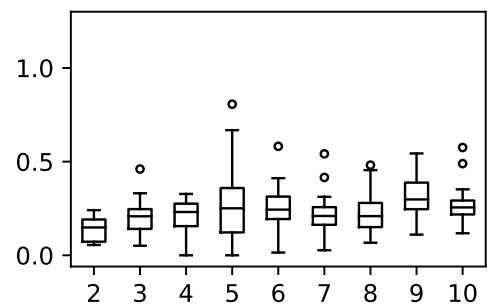

(h) T24

Figure 6: Disaggregated charging potential (in $\mathrm{kWh} / \mathrm{m}^{2}$ ) per eMBT for each month of the year.

\subsubsection{Charging from solar $P V$}

We evaluated the potential for charging the eMBTs from solar PV, both to reduce the load on the electrical grid and to reduce the size of the battery installed in the eMBT. The energy generated per surface area is shown in Figure $5 \mathrm{c}$ for each month of the year, representing an upper bound of charging potential during stationary periods.

The aggregate charging potential per square metre of solar panel, for the fleet, is shown in Figure $5 \mathrm{~d}$, indicating that a large amount of the generated energy could be used during stops. The disaggregated distribution of charging potential for each taxi, per square metre of solar panel, is shown in Figure $6{ }^{* 1}$ Despite the fact that the taxis followed slightly different stopping patterns, as discussed in Section 3.1, this figure

\footnotetext{
${ }^{* 1}$ Some of the taxis have less than 10 months of data due to errors in data-collection.
} 
indicates that the variation of charging potential between taxis is low, and that they would thus require similar charging infrastructure. Assuming that the PV installations were sized to exploit the median stop potential per taxi, the mean potential would be $0.34 \mathrm{kWh} / \mathrm{m}^{2}$ and would vary from a minimum of $0.24 \mathrm{kWh} / \mathrm{m}^{2}$ to a maximum of $0.52 \mathrm{kWh} / \mathrm{m}^{2}$ during the year. The results show that a solar installation of approximately $660 \mathrm{~m}^{2}$ would be required per taxi to ensure that the taxis' daily energy requirements would be met on an average day ${ }^{* 2}$ In other words, a PV installation the size of a football (soccer) field would be enough to meet the energy requirements of ten taxis $50 \%$ of the time.

Given the estimated 25,000 MBTs in Kampala [80, 82, our analysis indicates that to charge all the minibus taxis from the national grid will require $19 \%(5.6 \mathrm{GWh} / \mathrm{d})$ of the current daily national energy generation 68 .

\section{Conclusion}

Concern about the possible effects of climate change has driven an energy revolution from internal combustion engines to electric vehicles in the Global North. Pushed by market forces and supplier preferences from beyond its own borders, this wave will eventually break over the Global South and its organically evolved and notoriously chaotic paratransit systems and fragile electrical grids. Sub-Saharan Africa has many specific characteristics, challenges, and opportunities that will eventually determine its response.

This paper focuses on paratransit in the region, which transports more than $70 \%$ of the region's commuters. One of the unanswered questions is how the dissimilar mobility characteristics of the minibus taxis, the mainstay of the region's paratransit system, will translate into electrical requirements. Since these taxis park spontaneously at tacitly known stops of the drivers' choosing, for durations determined by passenger demand, the capacity of charging infrastructure at these stops is unknown. Further, the extent to which these charging stations can be powered by the region's abundant sunshine remains unclear.

This paper therefore investigated these three unknowns for minibus taxis, using an urban scenario in Kampala, Uganda, as a case-study.

Firstly, the results showed that the taxis we studied would mostly have a similar energy demand with a nominal $220 \mathrm{kWh}$ required per median day if no additional charging capacity was provided. This would increase to $375 \mathrm{kWh}$ when accommodating all days, except for two taxis, which required up to $491 \mathrm{kWh}$.

Secondly, evaluating the charging potential showed that the median stops per day ranged from $8 \mathrm{~h}$ to $12 \mathrm{~h}$. As expected, the taxis with the shorter stop periods, and hence less time for charging, are also the ones that would need more energy because they are more mobile. Nevertheless, a nominal $41 \mathrm{~kW}$ charger will suffice if

\footnotetext{
${ }^{*} 2$ The PV area to meet the taxis' daily energy requirements on an average day was calculated by dividing the mean $50^{t h}$ percentile of energy demand by the mean $50^{t h}$ percentile of charging potential.
} 
charging from a fully operational grid.

Finally, evaluating the solar irradiation for the stop times and durations, showed that the mean charging potential per median day ranged from $0.24 \mathrm{kWh} / \mathrm{m}^{2}$ to $0.52 \mathrm{kWh} / \mathrm{m}^{2}$. This implied that around $660 \mathrm{~m}^{2}$ (half of an Olympic swimming pool) of PV would be required to meet the taxi's energy demand on an average day.

Although the paper's results focus on specific case-study, for the first time, a rough estimate of the of the energy requirements of SSA's minibus taxis has been found. Firstly, it is clear that a substantial amount of energy is needed to support the mobility requirements of minibus taxis. This can be an obstacle for developing countries with energy insecurities. Regardless, renewable sources of energy should be found to offset this energy demand and to ascertain a sustainable transition to electric vehicles. We see that, conflicting to this need, a substantial investment would be needed to ensure that sufficient renewable power generation capacity is installed.

The instructive approach of this article should provide traffic planners and grid operators with a methodology to evaluate the impact of electric vehicle roll-outs in other regions of the world. The methodology can be adapted to suit mass roll-outs in developing countries, as well as roll-outs in small, privately owned fleets such as courier vans in a developed country.

Some further work is envisaged. Firstly, seasonal variation of the results may need to be taken into account. In Winter months, heating may increase energy usage, and solar irradiation would be less. This effect was not seen in this paper, due to Kampala being on the equator. Secondly, a structured approach to calculate the optimum battery size of the taxis would help for approximating the vehicle cost and feasibility. The duration of stops and energy consumed between stops would need to be taken into account when determining the battery size.

\section{Acknowledgements}

We acknowledge MTN South Africa (Contract S003061), Eskom (Tertiary Education Support Programme) and the National Research Foundation of South Africa (Reference number: MND200609529659) for funding this research through the MTN Mobile Intelligence Lab.

\section{References}

[1] K. A. Collett and S. A. Hirmer. Data needed to decarbonize paratransit in Sub-Saharan Africa. Nature Sustainability, 4(7):562-564, 2021. ISSN 2398-9629. doi: 10.1038/s41893-021-00721-7. URL https://rdcu.be/ckzez 
[2] R Behrens, D McCormick, and D Mfinanga. Paratransit in African cities: Operations, regulation and reform. Routledge, London, 1 edition, 2015. ISBN 9781315849515. doi: 10.4324/9781315849515.

[3] Daniel Ehebrecht, Dirk Heinrichs, and Barbara Lenz. Motorcycle-taxis in sub-Saharan Africa: Current knowledge, implications for the debate on "informal" transport and research needs. Journal of Transport Geography, 69:242-256, 2018. ISSN 0966-6923. doi: https://doi.org/10.1016/j.jtrangeo.2018.05.006.

[4] Roger Behrens, Dorothy McCormick, Risper Orero, and Marilyn Ommeh. Improving paratransit service: Lessons from inter-city matatu cooperatives in Kenya. Transport Policy, 53:79-88, 2017. ISSN 0967-070X. doi: https://doi.org/10.1016/j.tranpol.2016.09.003.

[5] Edna Odhiambo, Dan Kipkoech, Mohamed, Mikhail Manuel, Herrie Schalekamp, and Abdelrahman Hegazy Klopp, Jacquiline. The potential for minibus electrification in three african cities: Cairo, nairobi, and cape town. Volvo Research and Educational Foundations, 2021. doi: 10.13140/RG.2.2.26552. 26882.

[6] Katherine A. Collett, Stephanie A. Hirmer, Holger Dalkmann, Constance Crozier, Yacob Mulugetta, and Malcolm D. McCulloch. Can electric vehicles be good for sub-saharan africa? Energy Strategy Reviews, 38:100722, 2021. ISSN 2211-467X. doi: 10.1016/j.esr.2021.100722.

[7] Sajad Askari, Farideddin Peiravian, Nebiyou Tilahun, and Maryam Yousefi Baseri. Determinants of users' perceived taxi service quality in the context of a developing country. Transportation Letters, 13(2): 125-137, 2 2021. ISSN 1942-7867. doi: 10.1080/19427867.2020.1714844.

[8] Gail Jennings and Roger Behrens. The case for investing in paratransit: Strategies for regulation and reform. 1 2017. URL https://trid.trb.org/view/1660898.

[9] Innocent Ndibatya and M J Booysen. Characterizing the movement patterns of minibus taxis in Kampala's paratransit system. Journal of Transport Geography, 92:103001, 2021. ISSN 0966-6923. doi: https://doi.org/10.1016/j.jtrangeo.2021.103001.

[10] Andreas Neumann and Johan W. Joubert. The "Minibus" Contribution. In Andreas Horni, Kai Nagel, and Kay W Axhausen, editors, The Multi-Agent Transport Simulation MATSim. Ubiquity Press, London, 8 2016. doi: 10.5334/baw.17.

[11] G. Falchetta, M. Noussan, and A.T. Hammad. Comparing paratransit in seven major african cities: An accessibility and network analysis. Journal of Transport Geography, 94:103131, 2021. ISSN 0966-6923. doi: https://doi.org/10.1016/j.jtrangeo.2021.103131. URL https://www.sciencedirect.com/science/ article/pii/S0966692321001848. 
[12] W Mutiso and Roger Behrens. 'Boda Boda' bicycle taxis and their role in urban transport systems: case studies of Kisumu and Nakura, Kenya. In 30th Annual Southern African Transport Conference 11-14 July 2011 "Africa on the Move", CSIR International Convention Centre, pages 430-444, Pretoria, South Africa, 2011. URL http://hdl.handle.net/2263/17308.

[13] M J Booysen, S J Andersen, and A S Zeeman. Informal public transport in Sub-Saharan Africa as a vessel for novel Intelligent Transport Systems. In 16th International IEEE Conference on Intelligent Transportation Systems (ITSC 2013), pages 767-772, 10 2013. doi: 10.1109/ITSC.2013.6728324.

[14] Lourdes Diaz Olvera, Didier Plat, and Pascal Pochet. Looking for the obvious: Motorcycle taxi services in Sub-Saharan African cities. Journal of Transport Geography, page 102476, 7 2019. ISSN 0966-6923. doi: 10.1016/J.JTRANGEO.2019.102476.

[15] James Evans, Jennifer O'Brien, and Beatrice Ch Ng. Towards a geography of informal transport: Mobility, infrastructure and urban sustainability from the back of a motorbike. Transactions of the Institute of British Geographers, 43(4):674-688, 2018. doi: 10.1111/tran.12239.

[16] Mccormick Dorothy, Schalekamp Herrie, and Mfinanga David. The nature of paratransit operations. In Behrens Roger, McCormick Dorothy, and Mfinanga David, editors, Paratransit in African Cities: Operations, Regulation and Reform, chapter 3, pages 59-78. Routledge, New York, 1 edition, 2016. ISBN 9781315849515 .

[17] KCCA. Multimodal Urban Transport Master Plan for Greater Kampala Metropolitan Area. Technical report, Kampala Capital City Authority (KCCA), Kampala, 2016.

[18] Raffaello Cervigni, John Allen Rogers, and Irina Dvorak. Assessing Low-Carbon Development in Nigeria : An Analysis of Four Sectors. World Bank, Washington, DC, 2013. URL https://openknowledge. worldbank.org/handle/10986/15797.

[19] Monica Crippa, Guizzardi Oreggioni, Diego Guizzardi, Marilena Muntean, Edwin Schaaf, Eleonora Lo Vullo, Efisio Solazzo, Fabio Monforti-Ferrario, Jos GJ Olivier, and Elisabetta Vignati. Fossil co2 and ghg emissions of all world countries. Publication Office of the European Union: Luxemburg, 2019. URL https://op.europa.eu/en/publication-detail/-/publication/ 71b9adf3-f3dc-11ea-991b-01aa75ed71a1

[20] Shona Dalal, Juan Jose Beunza, Jimmy Volmink, Clement Adebamowo, Francis Bajunirwe, Marina Njelekela, Dariush Mozaffarian, Wafaie Fawzi, Walter Willett, Hans-Olov Adami, and Michelle D Holmes. 
Non-communicable diseases in sub-Saharan Africa: what we know now. International Journal of Epidemiology, 40(4):885-901, 3 2011. ISSN 0300-5771. doi: https://doi.org/10.1093/ije/dyr050.

[21] A Kofi Amegah and Samuel Agyei-Mensah. Urban air pollution in Sub-Saharan Africa: Time for action. Environmental Pollution, 220:738-743, 2017. ISSN 0269-7491. doi: https://doi.org/10.1016/j.envpol.2016. 09.042 .

[22] Wikimedia Contributors. File:Imf-advanced-un-least-developed-2008.svg, 2021. URL https://commons. wikimedia.org/wiki/File: Imf-advanced-un-least-developed-2008.svg. [Online; accessed 20. Aug. 2021].

[23] Ajay Mahaputra Kumar. Understanding the emerging role of motorcycles in African cities : a political economy perspective. Technical Report 13, Washington, DC: World Bank, Washington, DC, 2011.

[24] Ajay Mahaputra Kumar, Vivien Foster, and Fanny Barrett. Stuck in traffic : urban transport in Africa. Technical report, Washington, DC: World Bank, 2008. URL http://siteresources.worldbank.org/ EXTAFRSUBSAHTRA/Resources/Stuck-in-Traffic.pdf.

[25] Robert Cervero and Aaron Golub. Informal transport: A global perspective. Transport Policy, 14(6): 445-457, 11 2007. ISSN 0967-070X. doi: 10.1016/J.TRANPOL.2007.04.011.

[26] Karen Lucas, Gail Jennings, Mark Zuidgeest, Roger Behrens, Christo Venter, Winnie Mitullah, and Bronwen Thornton. Transport Social Exclusion in Five African Cities. Technical report, International Network for Transport and Accessibility in Low Income Communities, Leeds,UK, 2019. URL http://www.vref.se/download/18.45182a5f16a84e95fac8b2b5/1561370471910/Transport\% 20and $\% 20$ Social\%20Exclusion\%20in\%20five\%20African\%20Cities $\% 20-\% 20$ June\%202019.pdf

[27] Christo Venter, Anjali Mahendra, and Dario Hidalgo. From Mobility to Access for All: Expanding Urban Transportation Choices in the Global South. Technical report, World Resources Institute, 2019.

[28] Dorina Pojani and Dominic Stead. The Urban Transport Crisis in Emerging Economies: An Introduction. In Dorina Pojani and Dominic Stead, editors, The Urban Transport Crisis in Emerging Economies, pages 1-10. Springer International Publishing, Cham, 2017. ISBN 978-3-319-43851-1. doi: 10.1007/ 978-3-319-43851-1_1.

[29] Dorina Pojani and Dominic Stead. Policy design for sustainable urban transport in the global south. Policy Design and Practice, 1(2):90-102, 2018. doi: 10.1080/25741292.2018.1454291. 
[30] Daniel E Agbiboa. 'No Condition Is Permanent': Informal Transport Workers and Labour Precarity in Africa's Largest City. International Journal of Urban and Regional Research, 40(5):936-957, 92016. ISSN 0309-1317. doi: https://doi.org/10.1111/1468-2427.12440.

[31] I. Ndibatya and M.J. Booysen. Transforming Paratransit in Africa's congested Cities: An ICT- enabled Integrated Demand Responsive Transport (iDRT) approach. In Cunningham Miriam and Cunningham Paul, editors, IST-Africa 2020 Conference Proceedings, pages 1-10, Kampala, Uganda, 5 2020. IST-Africa Institute and IIMC. ISBN 9781905824656. URL www.IST-Africa.org/Conference2020

[32] Jacqueline M. Klopp. From "para-transit" to transit? power, politics and popular transport. Advances in Transport Policy and Planning. Academic Press, 2021. doi: https://doi.org/10.1016/bs.atpp.2021.07.002. URL https://www.sciencedirect.com/science/article/pii/S2543000921000317

[33] Tom Goodfellow. 'Double Capture' and De-Democratisation: Interest Group Politics and Uganda's 'Transport Mafia'. The Journal of Development Studies, 53(10):1568-1583, 2017. doi: 10.1080/00220388. 2016.1214722 .

[34] David Hecht. Invisible Governance: The Art of African Micropolitics . Autonomedia, New Yoork, 42007.

[35] C.J. Abraham, A.J. Rix, I. Ndibatya, and M.J. Booysen. Ray of hope for sub-Saharan Africa's paratransit: Solar charging of urban electric minibus taxis in South Africa. Energy for Sustainable Development, 64:118-127, 2021. ISSN 0973-0826. doi: https://doi.org/10.1016/j.esd.2021.08.003. URL https://www. sciencedirect.com/science/article/pii/S0973082621000946

[36] Roland Zinkernagel, James Evans, and Lena Neij. Applying the SDGs to Cities: Business as Usual or a New Dawn? Sustainability, 10(9), 2018. ISSN 2071-1050. doi: 10.3390/su10093201.

[37] Nancy Lozano Gracia, Engineer Bainomugisha, Maria Edisa Soppelsa, and Deo Okure. Characterization of Ambient Air Quality in Selected Urban Areas in Uganda : A Low-Cost Approach. Technical Report 9512, 2021. URL https://ideas.repec.org/p/wbk/wbrwps/9512.html.

[38] Ajit Singh, William R Avis, and Francis D Pope. Visibility as a proxy for air quality in East Africa. Environmental Research Letters, 15(8):84002, 7 2020. doi: 10.1088/1748-9326/ab8b12.

[39] Fiona Rajé, Miles Tight, and Francis D Pope. Traffic pollution: A search for solutions for a city like Nairobi. Cities, 82:100-107, 2018. ISSN 0264-2751. doi: https://doi.org/10.1016/j.cities.2018.05.008.

[40] World Health Organization et al. Indicator 3.9.1: Mortality rate attributed to household and ambient air pollution (per $100 \quad 000$ population), 2018. 

ambient-and-household-air-pollution-attributable-death-rate-(per-100-000-population).

[Online; accessed 10. Aug. 2021].

[41] United Nations, Department of Economic and Social Affairs, Population Division. World Population Prospects 2019, custom data acquired via website, 2019. URL https://population.un.org/wpp/ DataQuery. [Online; accessed 10. Aug. 2021].

[42] Worldometers.info. Reported Cases and Deaths by Country or Territory, Oct 2021. URL https: //www.worldometers.info/coronavirus/\#countries. [Online; accessed 16. Oct. 2021].

[43] J Akumu. Improving air quality in African cities. UN Environment, Nairobi, 2014.

[44] Anthony Black, Justin Barnes, Brian Makundi, and Tobias Ritter. Electric two-wheelers in Africa? Markets, production and policy Conference on Green Transformation and Competitive Advantage Evidence from developing countries. 32018.

[45] Elias Biryabarema. Ugandan auto firm aims to start producing buses this year, Mar 2021. URL https://www.reuters.com/article/uk-uganda-manufacturing-idUSKCN2AU11J., [Online; accessed 10. Jul. 2021].

[46] Richard M. Kavuma. Uganda's first electric car proves the potential of Africa's universities, Oct 2020. URL https://www.theguardian.com/global-development/poverty-matters/2011/nov/10/ uganda-electric-car-education. [Online; accessed 10. Jul. 2021].

[47] Jakub Galuszka, Emilie Martin, Alphonse Nkurunziza, Judith Achieng' Oginga, Jacqueline Senyagwa, Edmund Teko, and Oliver Lah. East Africa's Policy and Stakeholder Integration of Informal Operators in Electric Mobility Transitions-Kigali, Nairobi, Kisumu and Dar es Salaam. Sustainability, 13(4), 2021. ISSN 2071-1050. doi: 10.3390/su13041703.

[48] Oliver Lah. Decarbonizing the transportation sector: policy options, synergies, and institutions to deliver on a low-carbon stabilization pathway. WIREs Energy and Environment, 6(6):e257, 2017. doi: https://doi.org/10.1002/wene.257.

[49] Thi Phuong Linh Le and Tu Anh Trinh. Encouraging Public Transport Use to Reduce Traffic Congestion and Air Pollutant: A Case Study of Ho Chi Minh City, Vietnam. Procedia Engineering, 142:236-243, 2016. ISSN 1877-7058. doi: https://doi.org/10.1016/j.proeng.2016.02.037. 
[50] Louisa K Osei, Omid Ghaffarpasand, and Francis D Pope. Real-World Contribution of Electrification and Replacement Scenarios to the Fleet Emissions in West Midland Boroughs, UK. Atmosphere, 12(3), 2021. ISSN 2073-4433. doi: 10.3390/atmos12030332.

[51] Fred Krüger, Alexandra Titz, Raphael Arndt, Franziska Groß, Franziska Mehrbach, Vanessa Pajung, Lorenz Suda, Martina Wadenstorfer, and Laura Wimmer. The Bus Rapid Transit (BRT) in Dar es Salaam: A Pilot Study on Critical Infrastructure, Sustainable Urban Development and Livelihoods. Sustainability, 13(3), 2021. ISSN 2071-1050. doi: 10.3390/su13031058.

[52] Remy Sietchiping, Melissa Jane Permezel, and Claude Ngomsi. Transport and mobility in sub-Saharan African cities: An overview of practices, lessons and options for improvements. Cities, 29(3):183-189, 2012. ISSN 0264-2751. doi: https://doi.org/10.1016/j.cities.2011.11.005.

[53] Andalib Shams and Milan Zlatkovic. Effects of capacity and transit improvements on traffic and transit operations. Transportation Planning and Technology, 43(6):602-619, 2020. doi: 10.1080/03081060.2020. 1780710.

[54] Christoffel Venter, Gail Jennings, Darío Hidalgo, and Andrés Felipe Valderrama Pineda. The equity impacts of bus rapid transit: A review of the evidence and implications for sustainable transport. International Journal of Sustainable Transportation, 12(2):140-152, 2018. doi: 10.1080/15568318.2017. 1340528.

[55] I. Ndibatya and M. J. Booysen. Minibus taxis in Kampala's paratransit system: Operations, economics and efficiency. Journal of Transport Geography, 88, 2020. ISSN 09666923. doi: 10.1016/j.jtrangeo.2020.102853.

[56] Jiuyu Du, Minggao Ouyang, and Jingfu Chen. Prospects for Chinese electric vehicle technologies in 2016-2020: Ambition and rationality. Energy, 120:584-596, 2017. ISSN 0360-5442. doi: https: //doi.org/10.1016/j.energy.2016.11.114.

[57] Martin Weiss, Kira Christina Cloos, and Eckard Helmers. Energy efficiency trade-offs in small to large electric vehicles. Environmental Sciences Europe, 32(1):46, 2020. ISSN 2190-4715. doi: 10.1186/ s12302-020-00307-8.

[58] Ying Li, Chris Davis, Zofia Lukszo, and Margot Weijnen. Electric vehicle charging in China's power system: Energy, economic and environmental trade-offs and policy implications. Applied Energy, 173: 535-554, 2016. ISSN 0306-2619. doi: https://doi.org/10.1016/j.apenergy.2016.04.040.

[59] Maximilian Schücking, Patrick Jochem, Wolf Fichtner, Olaf Wollersheim, and Kevin Stella. Charging strategies for economic operations of electric vehicles in commercial applications. Transportation Research 
Part D: Transport and Environment, 51:173-189, 2017. ISSN 1361-9209. doi: https://doi.org/10.1016/j. $\operatorname{trd} .2016 .11 .032$.

[60] K M Buresh, M D Apperley, and M J Booysen. Three shades of green: Perspectives on at-work charging of electric vehicles using photovoltaic carports. Energy for Sustainable Development, 57:132-140, 2020. ISSN 0973-0826. doi: https://doi.org/10.1016/j.esd.2020.05.007.

[61] Atul S Jadhav, Dickson K Chembe, Johann M Strauss, and Johannes L Van Niekerk. Status of Solar Technology Implementation in the Southern African Developing Community (SADC) Region. Renewable and Sustainable Energy Reviews, 73:622-631, 2017. ISSN 1364-0321. doi: https://doi.org/10.1016/j.rser. 2017.01.113.

[62] J Quirós-Tortós, A N Espinosa, L F Ochoa, and T Butler. Statistical Representation of EV Charging: Real Data Analysis and Applications. In 2018 Power Systems Computation Conference (PSCC), pages 1-7, 2018. doi: 10.23919/PSCC.2018.8442988.

[63] DigitalTransport4Africa. Data, 2021. URL https://git.digitaltransport4africa.org/data. [Online; accessed 17. Oct. 2021].

[64] Windmanagda Sawadogo, Michelle Simões Reboita, Aissatou Faye, Rosmeri Porfírio da Rocha, Romaric C Odoulami, Christiana F Olusegun, Mojisola Oluwayemisi Adeniyi, Babatunde J Abiodun, Mouhamadou Bamba Sylla, Ismaila Diallo, Erika Coppola, and Filippo Giorgi. Current and future potential of solar and wind energy over Africa using the RegCM4 CORDEX-CORE ensemble. Climate Dynamics, 2020. ISSN 1432-0894. doi: 10.1007/s00382-020-05377-1.

[65] Pedro M M Soares, Miguel C Brito, and João A M Careto. Persistence of the high solar potential in Africa in a changing climate. Environmental Research Letters, 14(12):124036, 12 2019. doi: 10.1088/ 1748-9326/ab51a1.

[66] I. Ndibatya, M.J. Booysen, and J. Quinn. An adaptive transportation prediction model for the informal public transport sector in Africa. In 2014 17th IEEE International Conference on Intelligent Transportation Systems, ITSC 2014, 2014. ISBN 9781479960781. doi: 10.1109/ITSC.2014.6958102.

[67] Samuel Vivian Matagi. Some issues of environmental concern in kampala, the capital city of uganda. Environmental monitoring and assessment, 77(2):121-138, 2002.

[68] USAID. Power Africa in Uganda, 05 2019. URL https://www.usaid.gov/powerafrica/uganda. (Archived: https://web.archive.org/web/20210428002702/https://www.usaid.gov/powerafrica/ uganda) [Online; accessed 10. Jul. 2021]. 
[69] World Bank. Ugandan Government Steps Up Efforts to Mitigate and Adapt to Climate Change, May 2019. URL https://www.worldbank.org/en/news/feature/2019/05/31/ ugandan-government-steps-up-efforts-to-mitigate-and-adapt-to-climate-change. [Online; accessed 14. Oct. 2021].

[70] Nate Blair, Aron P Dobos, Janine Freeman, Ty Neises, Michael Wagner, Tom Ferguson, Paul Gilman, and Steven Janzou. System Advisor Model, SAM 2014.1.14: General Description. 3 2014. doi: 10.2172/1126294. URL https://www.osti.gov/biblio/1126294.

[71] Pablo Alvarez Lopez, Michael Behrisch, Laura Bieker-Walz, Jakob Erdmann, Yun-Pang Flötteröd, Robert Hilbrich, Leonhard Lücken, Johannes Rummel, Peter Wagner, and Evamarie Wießner. Microscopic Traffic Simulation using SUMO. In 2019 IEEE Intelligent Transportation Systems Conference (ITSC), pages 2575-2582. IEEE, 11 2018. URL https://elib.dlr.de/127994/.

[72] Tamás Kurczveil, Pablo Álvarez López, and Eckehard Schnieder. Implementation of an Energy Model and a Charging Infrastructure in SUMO. In Michael Behrisch, Daniel Krajzewicz, and Melanie Weber, editors, Simulation of Urban Mobility, pages 33-43, Berlin, Heidelberg, 2014. Springer Berlin Heidelberg. ISBN 978-3-662-45079-6.

[73] Yu Zheng, Lizhu Zhang, Xing Xie, and Wei-Ying Ma. Mining Interesting Locations and Travel Sequences from GPS Trajectories. In Proceedings of the 18th International Conference on World Wide Web, WWW '09, pages 791-800, New York, NY, USA, 2009. Association for Computing Machinery. ISBN 9781605584874. doi: 10.1145/1526709.1526816.

[74] Maria Luisa Damiani, Hamza Issa, and Francesca Cagnacci. Extracting Stay Regions with Uncertain Boundaries from GPS Trajectories: A Case Study in Animal Ecology. In Proceedings of the 22nd ACM SIGSPATIAL International Conference on Advances in Geographic Information Systems, SIGSPATIAL '14, pages 253-262, New York, NY, USA, 2014. Association for Computing Machinery. ISBN 9781450331319. doi: $10.1145 / 2666310.2666417$.

[75] OpenStreetMap contributors. Planet dump retrieved from https://planet.osm.org . https://www.openstreetmap.org, 2017.

[76] Rhyd Lewis. Algorithms for Finding Shortest Paths in Networks with Vertex Transfer Penalties. Algorithms, 13(11), 2020. ISSN 1999-4893. doi: 10.3390/a13110269.

[77] Joakim Fridlund and Oliver Wilen. Parameter Guidelines for Electric Vehicle Route Planning, 2020. 
[78] Manajit Sengupta, Yu Xie, Anthony Lopez, Aron Habte, Galen Maclaurin, and James Shelby. The National Solar Radiation Data Base (NSRDB). Renewable and Sustainable Energy Reviews, 89:51-60, 2018. ISSN 1364-0321. doi: https://doi.org/10.1016/j.rser.2018.03.003.

[79] Mark Z Jacobson and Vijaysinh Jadhav. World estimates of pv optimal tilt angles and ratios of sunlight incident upon tilted and tracked pv panels relative to horizontal panels. Solar Energy, 169:55-66, 2018.

[80] Dave Spooner, John Mark Mwanika, Shadrack Natamba, and Erick Oluoch Manga. Kampala bus rapid transit: Understanding kampala's paratransit market structure, 2020. URL https://www.researchgate. net/profile/Dave-Spooner/publication/342233740_Kampala_Bus_Rapid_Transit_ Understanding_Kampala's_Paratransit_Market_Structure/links/5ee9f250a6fdcc73be82f860/ Kampala-Bus-Rapid-Transit-Understanding-Kampalas-Paratransit-Market-Structure.pdf.

[81] Zhiming Gao, Zhenhong Lin, Tim J. LaClair, Changzheng Liu, Jan-Mou Li, Alicia K. Birky, and Jacob Ward. Battery capacity and recharging needs for electric buses in city transit service. Energy, 122:588-600, 2017. ISSN 0360-5442. doi: https://doi.org/10.1016/j.energy.2017.01.101. URL https: //wWw.sciencedirect.com/science/article/pii/S0360544217301081.

[82] Regina Kamuhanda and Oliver Schmidt. Matatu: A case study of the core segment of the public transport market of kampala, uganda. Transport Reviews, 29(1):129-142, 2009. 